\title{
O tratamento de pré-emergência com o 2, 4-D no milho
}

HEITOR W. S. MONTENEGRO E HELMUT PAULO KRUG

INDICE

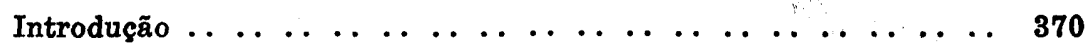

Materiais e Métodos . . . . . . . . . . . . . . . . . . . . . . 370

Dados obtidos e sua análise . . . . . . . . . . . . . . . . . . . . . 371

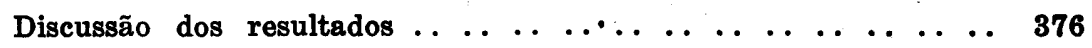

Resumo e Conclusões .. . . . . . . . . . . . . . . . . . . 878

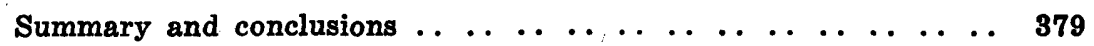

Agradecimentos . . . . . . . . . . . . . . . . . . . . . . . . . . . . . 38

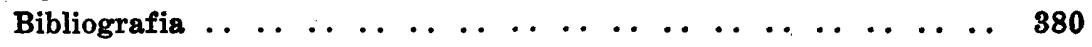




\section{INTRODUÇÃO}

Experiências realizadas em outros países constataram a possibilidade do contrôle de ervas más pelo 2,4-D nas culturas de milho.

Dois são os métodos empregados; o primeiro chamado tratamento de pré-emergência e o segundo de post-emergência. O primeiro método se refere ao tratamento feito depois da semeadura do milho porém antes dêle emergir do solo. $O$ segundo, de post-emergência, é feito após a plantinha aflorar à superfície do solo.

Vamos tratar aqui apenas do primeiro método aplicado à cultura do milho.

Foi nosso intuito nesta experiência preliminar verificar a ação de diversos ervicidas em concentrações diferentes sôbre as ervas más e milho. Com os resultados obtidos estamos aptos a fazer êste ano novos experimentos neste campo mais simplificados, pelo uso de menos ervicidas porém mais completos devido à variação de solos e variedades de milho.

\section{MATERIAIS E METODOS}

Os ervicidas usados foram em número de três : ácido 2,4-dicloro-fenoxiacético, nas suas diferentes formas: sais de sódio a $80 \%$, de amina a $40 \%$ e ester a $44 \%$; $2,4-5-\mathrm{T}$ a $43 \%$ e TCA $70 \%$.

Usamos duas concentrações de cada ervicida sendo uma o dôbro da outra. Os tratamentos foram assim especificados:

\section{Tratamentos}

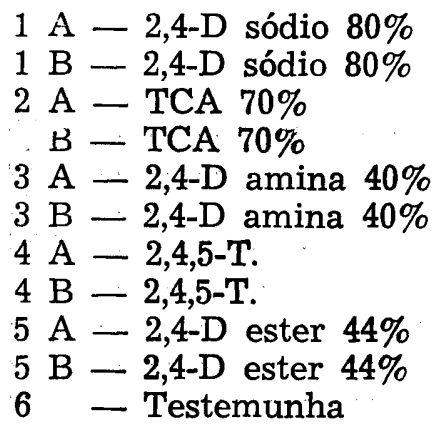

$\begin{array}{lr}\text { na concentração de } & 5: 1000 \\ \text { na concentração de } & 2,5: 1000 \\ \text { na concentração de } & 12: 1000 \\ \text { na concentração de } & 6: 1000 \\ \text { na concentração de } & 2,5: 1000 \\ \text { na concentração de } & 1,25: 1000 \\ \text { na concentração de } & 3: 1000 \\ \text { na concentração de } & 1,5: 1000 \\ \text { na concentração de } & 5: 1000 \\ \text { na concentração de } & 2,5: 1000\end{array}$

A falta de dados sôbre a concentração de cada produto, no início da experiência, deu como causa, uma variação de todos os tratamentos na concentração a base de ácido 2,4-D puro. 
O milho utilizado no ensaio foi o híbrido duro I. A. 35-31 em parcelas de $4 \times 5$ metros em 3 repetições e distribuidos ao acaso. Em cada lote havia 5 linhas de milho, sendo que para efeito dos resultados foram computadas apenas as 5 linhas internas.

O ensaio foi localizado em um terreno de terra roxa, junto ao viveiro de laranjeiras da Secção de Horticultura da Escola Superior de Agricultura "Luiz de Queiroz". Antes do preparo do terreno, procedemos a um levantamento das ervas más existentes nêle, com o seguinte resultado:

Carurú branco ou Picão branco - Alternanthera sp.

Amendoin bravo - Euforbia heterophyla, L.

Beldroega - Portulaca oleracea, L.

Couvitinga - Solanum verbascifolium, $L$.

Picão - Bideus binnatus, L.

Capim pé de galinha - Eleusine indica, Gaertn.

Carrapicho - Cenchrus echinatus, L.

Capim sempre verde - Poa nemoralis, $L$.

Cravorana - Erigeron bonariensis; $A$.

Serralha - Sónchus oleraceus, L.

Carrapicho de carneiro - Acanthospermum hispidum, DC.

Oficial de salas - Asclepias Aurassavica, L.

Macela - Achyrocline satureoides, DC:

Capim catingueiro - Panicum monostachyum, HBK

Erva moura - Solanum nigrum, L.

Capim de Rhodes - Chloris gayana, Kunth.

Flor de São João - Pyrostegia venusta, Miers.

A semeadura do milho foi feita em 14 de Dezembro de 1950 e o tratamento feito em 18 do mesmo mês, dois dias antes das plantinhas emergirem do solo. Cada lote de 20 metros quadrados recebeu 2 litros de solução nas concentraçóes acima referidas.

Dois fatôres foram estudados: $1^{\circ}$. contrôle das ervas más tanto gramíneas como não gramíneas e, segundo, sensibilidade do milho aos diversos ervicidas usados.

Não foi feita capina em nenhum dos tratamentos.

\section{DADOS OBTIDOS E SUA ANALISE}

Contrôle de ervàs más: Em 24 de Janeiro de 1951 procedemos ao levantamento das ervas más existentes nos lotes.

Com o fito de facilitar o trabalho, êstè serviçco foi feito, marcando-se em cada lote, quadrados de 1 metro de lado, á direita e à 'esquerda das linhas centrais, e distante 1,5 metro do 
início de cada parcela; nêles foram contadas as plantinhas de ervas daninhas existentes tanto de gramíneas como não gramíneas e para efeito de cálculo foi multiplicada sua frequência pela altura média das ervas.

Na tabela 1 damos os resultados obtidos

Tabela I - Contrôle de ervas daninhas em percentagens

\begin{tabular}{|c|c|c|}
\hline Tratamentos & Tipo de ervas & $\begin{array}{l}\text { Ervas más } \\
\text { Existentes }\end{array}$ \\
\hline $\begin{array}{l}1 \mathrm{~A}-2,4-\mathrm{D} \text { sódio } 80 \% \text { na } \\
\text { conc. }\end{array}$ & $\begin{array}{l}\text { Gramíneas } \\
\text { Não gramíneas }\end{array}$ & $\begin{array}{rl}5 \% & * * \\
0,3 \% & * *\end{array}$ \\
\hline $\begin{array}{l}\text { 1B - 2,4-D sódio } 80 \% \text { na } \\
\text { conc. } 2,5: 1000\end{array}$ & $\begin{array}{c}\text { Gramíneas } \\
\text { Não gramíneas }\end{array}$ & $\begin{array}{rl}16,2 \% & * * \\
5 \% & * *\end{array}$ \\
\hline $2 \mathrm{~A}-\underset{\text { conc. }}{\mathrm{TCA}} 70 \%$ na & $\begin{array}{c}\text { Gramíneas } \\
\text { Não gramíneas }\end{array}$ & $\begin{array}{l}13,1 \% * * \\
26,0 \% * *\end{array}$ \\
\hline $\begin{array}{l}2 \mathrm{~B}-\mathrm{TCA} 70 \% \text { na } \\
\text { conc. }\end{array}$ & $\begin{array}{c}\text { Gramíneas } \\
\text { Não gramíneas }\end{array}$ & $\begin{array}{l}17,6 \% \\
55,2 \% *\end{array}$ \\
\hline $\begin{array}{l}3 \mathrm{~A}-2,4-\mathrm{D} \text { amina } 40 \% \mathrm{na} \\
\text { conc. } \\
2,5: 1000\end{array}$ & $\begin{array}{c}\text { Gramíneas } \\
\text { Não gramíneas }\end{array}$ & $\begin{array}{l}6,5 \% * * \\
2,8 \% * *\end{array}$ \\
\hline $\begin{array}{cc}3 \mathrm{~B}-2,4-\mathrm{D} \text { amina } & 40 \% \text { na } \\
\text { conc. } & 1,25: 1000\end{array}$ & $\begin{array}{c}\text { Gramíneas } \\
\text { Não gramíneas }\end{array}$ & $\begin{array}{l}19,7 \% * * \\
17,5 \% * *\end{array}$ \\
\hline $\begin{array}{l}4 \mathrm{~A}-2,4-5-\mathrm{T} \text { na } \\
\text { conc. }\end{array}$ & $\begin{array}{c}\text { Gramíneas } \\
\text { Não gramíneas }\end{array}$ & $\begin{array}{rl}20,4 \% & * * \\
5,7 \% & * *\end{array}$ \\
\hline $\begin{array}{l}4 \mathrm{~B}-2,4-5-\mathrm{T} \% \text { na } \\
\text { conc. }\end{array}$ & $\begin{array}{c}\text { Gramíneas } \\
\text { Não gramíneas }\end{array}$ & $\begin{array}{l}27,2 \% * \\
15,1 \% * *\end{array}$ \\
\hline $\begin{array}{l}5 \mathrm{~A}-2,4-\mathrm{D} \text { ester } 44 \% \text { na } \\
\text { conc. }\end{array}$ & $\begin{array}{c}\text { Gramíneas } \\
\text { Não gramíneas }\end{array}$ & $\begin{array}{rl}24,6 \% & * * \\
2,8 \% & * *\end{array}$ \\
\hline $\begin{array}{l}5 \mathrm{~B}-2,4-\mathrm{D} \text { ester } 44 \% \text { na } \\
\text { conc. } 2,5: 1000\end{array}$ & $\begin{array}{c}\text { Gramíneas } \\
\text { Não gramíneas }\end{array}$ & $\begin{array}{rl}20,8 \% & * * \\
3,7 \% & * *\end{array}$ \\
\hline Testemunha & $\left|\begin{array}{c}\text { Gramíneas } \\
\text { Não gramíneas }\end{array}\right|$ & $\begin{array}{l}100 \% \\
100 \%\end{array}$ \\
\hline
\end{tabular}


Obeservando-se a tabela 1 podemos notar que :

a) os tratamentos $\mathrm{A}$, de maior concentração, controlaram melhor as ervas más, do que os de mais fraca concentração;

b) os tratamentos que apresentaram alto índice de contrôle das ervas daninhas não gramíneas foram em ordem decrescente $1 \mathrm{~A}, 5 \mathrm{~A}$ e $3 \mathrm{~A}$; para as gramíneas, foram $5 \mathrm{~A}, 1 \mathrm{~A}$ e $3 \mathrm{~A}$.

O TCA não apresentou os resultados esperados, de maior contrôle das gramíneas, já que êle é específico para elas.

\section{ANALISE ESTATISTICA}

As médias obtidas são as contidas nos quadros seguintes:

Gramineas

\begin{tabular}{l|c|c|c|c|c|c|c|c|c|c|c}
\hline Trat. & 1A & 1B & 2A & 2B & 3A & 3B & 4A & 4B & 5A & 5B & 6 \\
\hline Iédlla ob. $|51|$ & 51 & 165 & 134 & 179 & 67 & 201 & 208 & 278 & 47 & 212 & 669 \\
\hline
\end{tabular}

Não gramíneas

\begin{tabular}{l|c|c|c|c|c|c|c|c|c|c|c}
\hline Trat. & 1A & 1B & 2A & 2B & $3 \mathrm{~A}$ & 3B & $4 \mathrm{~A}$ & 4B & $5 \mathrm{~A}$ & $6 \mathrm{~B}$ & 6 \\
\hline Wédia ob. & 2 & 32 & 165 & 346 & 19 & 123 & 36 & 95 & 20 & 24 & 646 \\
\hline
\end{tabular}

Note-se que os tratamentos todos são muito diferentes do testemunha. Esta observação foi aproveitada na análise estatística, onde separámos de um todo a soma dos quadrados dos desvios devidos à diferença entre os tratamentos, e de outro lado a soma dos quadrados dos desvios devidos ao contraste entre os tratamentos, em conjunto, e a testemunha.

Os resultados da análise de variância são dados a seguir para as gramíneas.

\begin{tabular}{|c|c|c|c|c|}
\hline \multicolumn{2}{|c|}{$\begin{array}{l}\text { Causa de } \\
\text { variação }\end{array}$} & $\begin{array}{l}\text { Soma dos } \\
\text { quadrados }\end{array}$ & $\begin{array}{l}\text { Grau de } \\
\text { liberdade }\end{array}$ & Variância \\
\hline 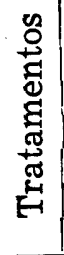 & $\begin{array}{l}\text { Contraste } \\
\text { entre a tes- } \\
\text { temunha e } \\
\text { os tratam. } \\
\text { Entre tra- } \\
\text { tamentos }\end{array}$ & $\begin{array}{r}1.325 .953 \\
163.524\end{array}$ & $\begin{array}{l}1 \\
9\end{array}$ & $\begin{array}{c}1.325 .953 * * * \\
18.169 \\
\end{array}$ \\
\hline & Resíduo & 1.056 .627 & 25 & 42.265 \\
\hline & Total & 2.546 .104 & 35 & - \\
\hline
\end{tabular}


Indicamos com três asteriscos a significação para o limite de $1 \%$ de probabilidade. Podemos calcular o êrro da diferença entre as médias de um tratamento e a média da testemunha. Obtemos :

$$
v \text { dif }=\sqrt{\frac{42265}{3}+\frac{42.265}{6}}=145,4
$$

A diferença mínima significativa é, pois, 405,7 , para o limite de $1 \%$.

Verifica-se, pelos dados expostos, que todos os tratamentos diferem da testemunha, tomando-se por base êsse valor, com exceção apenas do tratamento $4 \mathrm{~B}$, que apenas excede o limite de $5 \%$.

No caso das não gramíneas, a análise da variância deu os resultados seguintes :

\begin{tabular}{|c|c|c|c|c|}
\hline \multicolumn{2}{|r|}{$\begin{array}{l}\text { Causa de } \\
\text { variacão }\end{array}$} & $\begin{array}{l}\text { Soma dos } \\
\text { quadrados }\end{array}$ & $\begin{array}{l}\text { Grau de } \\
\text { liberdacle }\end{array}$ & Variância \\
\hline 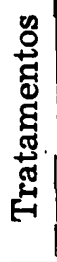 & $\begin{array}{l}\text { Contraste } \\
\text { entre a tes- } \\
\text { temunha e } \\
\text { os tratam. } \\
\text { Entre tra- } \\
\text { tamentos }\end{array}$ & $\begin{array}{r}2.542 .254 \\
301.450\end{array}$ & 1 & $\begin{array}{c}2.542 .254 * * * \\
33.494\end{array}$ \\
\hline & Resíduo & 806.618 & 25 & 32.265 \\
\hline & Total & $3.65 n, 322$ & 35 & - \\
\hline
\end{tabular}

O êrro entre a média de um tratamento e a média da testemunha será:

$$
\sigma \text { dif. }=\sqrt{\frac{32.265}{3}+\frac{32.265}{6}}=127,0
$$

Também neste caso se verifica que as diferenças entre as médias dos tratamentos e a da testemunha tôdas excedem o limite de $1 \%$, com exceção apenas do tratamento, $2 \mathrm{~B}$, que apenas ultrapassa o limite de $5 \%$. 


\section{SENSIBILIDADE DO MILHO AOS DIVERSOS ERVICIDAS}

Para o estudo dêste fator, alêm das observações feitas no início do cresciménto do milho, è medições de altura dos pés de milhos, pesamos a colheita' de espigas provenientes das três linhas do meio de cada lote.

As plantinhas de milho mostraram ser muito sensíveis ao TCA. Nos três lotes do tratamento $2 \mathrm{~A}$ - as plantinhas tiveram seus crescimentos estacionados, as fôlhas continuaram enroladas e retorcidas. (Fig.). Houve um grande número de falhas devido à morte das plantinhas raquíticas.

Os lotés trâtados ainda com o TCA, porém na concentração mais fraca, mostraram também os mesmos sintomas porém em menor intensïdade e pouco a poucó conseguiram se refazer.

As mediçốes de altura foram feitas no milho em 23 e 24 de Janeiro de 1951 e os resultados . . analizados . estatisticamente mostraram ser equivalentes com exceção do tratamento: $2 \mathrm{~A}$ que foi significativo; prejudicando o crescimento.

A colheita de espigas das três linhas centrais de cada lote foi pesada e os dadog analizados estatisticamente apresentaram os seguintes resultados:

Tabela 2 - Produção de milho

\begin{tabular}{|c|c|c|}
\hline Tratamento & Espigas de milhc (em grs.) & \\
\hline $\begin{array}{l}1 \mathrm{~A} \\
1 \mathrm{~B} \\
2 \mathrm{~A} \\
2 \mathrm{~B} \\
3 \mathrm{~A} \\
3 \mathrm{~B} \\
4 \mathrm{~A} \\
4 \mathrm{~B} \\
5 \mathrm{~A} \\
5 \mathrm{~B} \\
6\end{array}$ & $\begin{array}{r}19.730 \\
23.270 \ldots \\
8.350 \ldots \\
18.280 \\
17.640 \\
20.340 \\
18.410 \\
21.300 \ldots \\
22.400 \ldots \\
21.880 \ldots \\
16.830 \ldots\end{array}$ & $\begin{array}{l}* \\
* \\
*\end{array}$ \\
\hline
\end{tabular}

ANALISE ESTATISTICA

Médias de produção observadas :

\begin{tabular}{|c|c|c|c|c|c|c|c|c|c|c|c|}
\hline at. & $1 \mathrm{~A}$ & 1B & $2 A$ & 2B & $3 \mathrm{~A}$ & $3 \mathbf{B}$ & $4 A$ & $4 \mathrm{~B}$ & $5 \mathrm{~A}$ & $5 \mathrm{~B}$ & 6 \\
\hline . & 647 & 75 & 278 & 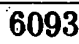 & 588 & 67 & 613 & $|7100| 7$ & 7466 & $7 \overline{729}$ & 561 \\
\hline
\end{tabular}


Damos a seguir os resultados da análise de variâncias :

\begin{tabular}{c|c|c|r}
\hline & $\begin{array}{c}\text { Soma dos } \\
\text { quadrados }\end{array}$ & $\begin{array}{c}\text { Grau de } \\
\text { liberdade }\end{array}$ & \multicolumn{1}{|c}{$\mathbf{2}$} \\
\hline & & & \\
Tratamento & 1194.326 .116 & 10 & 119.432 .611 \\
Resíduo & 224.536 .507 & 25 & 888.146 \\
Total & 35 & & \\
\hline
\end{tabular}

O êrro entre a média de um tratamento e a média da testemunha será :

$$
\sigma \text { dif. }=V 8 \overline{89.146}=974
$$

A diferença mínima significativa é, pois, 1866,3 para o limite de $1 \%$. Verifica-se, por êstes dados, que os tratamentos $1 \mathrm{~B}$ e $2 \mathrm{~A}$ diferem da testemunha. Os tratamentos $4 \mathrm{~B}, 5 \mathrm{~A}$ e $5 \mathrm{~B}$ apenas excedem o limite de $5 \%$.

Por êstes dados podemos ver que o único tratamento cujo ervicida teve efeito prejudicial na produção, foi o TCA em dosagem maior. Por outro lado, o tratamento $1 \mathrm{~B}$ foi significante no aumento de produção em relação à testemunha. Conquanto os tratamentos $4 \mathrm{~B}, 5 \mathrm{~A}$ e $5 \mathrm{~B}$ também tivessem sua produção aumentada, são, porém, os resultados estatìsticamente duvidosos. Os demais tratamentos se equivalem.

\section{DISCUSSAO DOS RESULTADOS}

No contrôle de ervas más, nos tratamentos com diferentes formulações de 2,4-D, 1A, 1B, 3A, 3B, 5A e 5B, nota-se acentuada variação do efeito ervicida dos diferentes radicais.

Se bem que êstes ervicidas estejam em diferentes concentrações a base de ácido 2,4-D puro, são comparáveis os tratamentos $1 \mathrm{~B}$ e $5 \mathrm{~A}$ com manifesta superioridade dêsse último (ester); o $5 \mathrm{~B}$ é comparável ao $3 \mathrm{~A}$, e ainda que êste último esteja em inferioridade de $325 \mathrm{~g}$. de ácido 2,4-D por hectare apresentou um superior contrôle de gramíneas.

E' portanto, dígno de nota o efeito do 2,4-D amina, que, em tão baixa concentração $600 \mathrm{~g}$. por hectare (na base de ácidọ 2,4-D) apresentou um contrôle de ervas más quase tão bom como o dado pelo 2,4-D sódio, se bem que êste estivesse em concentração quase seis vezes mais forte do que êle. Seu contrôle também, pode ser considerado igual ao efetuado pelo tratamento $5 \mathrm{~A}-2,4-\mathrm{D}$ ester - sendo que êste último estava três vezes mais concentrado (na base de ácido 2,4-D puro) . 
O TCA, demonstrou, como já esperávamos, não ser aconselhável no tratamento de pré-emergência do milho. Em concentração mais forte, doze por mil, prejudicou bastante a germinação, crescimento e produção do milho. Se contrôle de ervas más, também não foi dos melhores. Em concentração mais fraca, seis por mil, se bem que não tenha interferido com a produção, apresentou baixo contrôle de ervas principalmente não gramíneas.

Esse baixo contrôle de ervas do TCA se deve em parte ao seguinte : inicialmente êle agiu de maneira satisfatória, permanecendo os lotes limpos de ervas por cêrca de um mês; sendo êle mais fàcilmente lavado do que os outros ervicidas, após êsse tempo seus efeitos residuais tornaram-se quase nulos. Em razão do atrazo de crescimento dos pés de milho devido à ação direta do TCA sôbre êles, as entrelinhas não foram sombreadas, como aconteceu nos outros e isto favoreceu a germinação das sementes de ervas daninhas mais atrazadas e não afetadas inicialmente por êle.

O 2,4,5-T cuja ação ervicida é conhecida ser maior que a do 2,4-D quando em pulverizações feitas diretamente sôbre as ervas daninhas, não o demonstrou ser no tratamento de préemergência. Sendo êle um produto de bem maior preço que os outros a base de 2,4-D não se torna aconselhável, do ponto de vista econômico, o seu emprêgo no tratamento de pré-emergência no milho.

Analisando ainda a tabela I, podemos vêr que todos os tratamentos apresentaram ótimo contrôle de gramíneas, o que vem demonstrar uma grande superioridade do método de pré-emergência sôbre o de post-emergência. Éste último, em lugar de controlar as ervas daninhas gramíneas faz o inverso.

Isto foi constatado em nossas experiências com o 2,4-D em pulverização de post-emergência na cana.

No que se refere à produção de milho expressa na tabela 2, podemos notar que debaixo das condições climatéricas a que esteve sujeita nossa experiência (Boletins metereológico anexos) mesmo uma dose forte como a do tratamentos $1 \mathrm{~A}, 3.400 \mathrm{~g}$. (ácido 2,4-D) por hectare não interferiu na produção.

Analisando-se ainda a tabela 2 é visível a superioridade de todos os tratamentos, com exceção do $2 \mathrm{~A}$ que foi prejudicial, sôbre a testemunha.

Isto se deve, em primeiro lugar, à falta de competição entre os pés de milho e ervas daninhas, comparada com a testemunha que não foi capinada nenhuma vez; em segundo lugar, 
talvez tenha havido uma ação hormonial do 2,4-D no milho, após sua diluição pelas águas da chuva, incentivando-o a uma maior produção.

\section{RESUMO E CONCLUSÕES}

Com o fito de estudar a ação dos ervícidas : 2,4-D éster propílico, 2,4-D isopropanolamina, 2,4-D sódio, 2,4-5T e TCA no contrôle às ervas más no tratamento de prê-emergência no milho, foi elaborado um ensaio preliminar cujos tratamentos e respectivos resultados constam nas tabelas 1 e 2 .

O milho utilizado na experiência foi o híbrido duro IA-3531. Todos os tratamentos, com exceção do $2 \mathrm{~B}$, para as ervas más não gramíneas e o $4 \mathrm{~B}$ para as gramíneas que deram resultados duvidosos, são altamente significativos em relação à testemunha, no contrôle das ervas más.

Se bem que entre si não defiram significativamente notamos que: (Tabela I).

a) os tratamentos de maior concentração foram superiores aos de mais fraca concentração.

b) os tratamentos que melhor controlaram as ervas más não gramíneas foram em ordem decrescente: 1A, 5A e 3A; para as gramíneas foram $5 \mathrm{~A}, 1 \mathrm{~A}$ e $3 \mathrm{~A}$.

c) o 2,4-D amina apresentou um ótimo contrôle se levarmos em consideração que êle se achava em muito baixa concentração na base de ácido 2,4-D (600 g. por hectare) .

d) o TCA na concentração maior prejudicou a germinação, crescimento e produção; na mais fraca, não apresentou um bom contrôle de ervas principalmente não gramíneas. Não é aconselhável para êste fim.

e) o 2,4,5T não se sobressaiu com relação aos produtos a base de 2,4-D. Sendo um produto de muito maior preço que os de 2,4-D economicamente não é aconselhável o seu uso no tratamento de pré-emergência no milho.

f) todos os produtos utilizados controlaram ervas más gramíneas o que demonstra uma superioridade do método de préemergência sôbre o de post-emergência.

g) (Tabela II) mesmo uma dosagem tão forte com a do tratamento $1 \mathrm{~A}(3.400 \mathrm{~g}$. de ácido 2,4-D por hectare) não prejudicou a produção de milho,

h) a superioridade que se nota na produção de todos os tratamentos com exceção do $2 \mathrm{~A}$ que foi prejudicial, atribuimos a falta de competição entre os pés de milho e ervas más; a testemunha sofreu esta concorrência, pois não recebeu nenhuma capina. Talvez tenha, também, havido um efeito hormonial do 2,4-D no milho. 
Se bem que o presente experimento foi coroado de êxito, julgamos necessário novas perquisas, principalmente com o fito de conhecermos a ação dos fatôres clima e solo que, em outros paízes, demonstraram interferir no sucesso do tratamento de pré-emergência.

\section{SUMMARY AND CONCLUSIONS}

In order to study the action of herbicides - sodium salt, amine salt and ester of 2,4-D, TCA and 2,4,5-T a preliminary experiment for pre-emergence weed control was corried out, and the corresponding results are given in table I and II.

The corn used in the experiments was of the flint type $1 \mathrm{~A}$ 3531. The loam soil on which the experiment has been carried out is called "terra roxa".

All treatments were highly significant when compared with the check plots, except the $2 \mathrm{~B}$ one in the control of broad leaf weeds, and $4 \mathrm{~B}$ in the control of grass weeds.

Among these treatments there are no significant differences. But we note the following: (table I).

a) treatments of higher concentrations were superior to lower ones.

b) the treatments which gave the best control for broad leaf weeds were in the following decreasing order : $1 \mathrm{~A}, 5 \mathrm{~A}$ and $3 \mathrm{~A}$. For grass weeds, they were $5 \mathrm{~A}, 1 \mathrm{~A}$ and $3 \mathrm{~A}$.

c) the amine 2,4-D (600 grs. per hectare) supplied very good control when we get into consideration that on the acid basis, it was in very low concentration.

d) TCA in high concentration affected the germination, growth and yield, in the lower one it did not show good control of weeds, especially of grasses. It is not suitable for preemergence control in corn.

e) 2,4,5-T was not better than the 2,4-D products. As it is much more expensive than the others, economically its use in pre-emergence weed control in corn is not praticable.

f) all the products used controled grass weeds as well as broad leaf ones; this show the superiority of the pre-emergence treatment method over that of post-emergence.

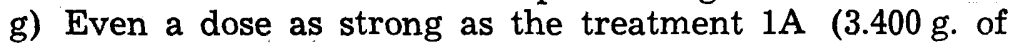
2,4-D acid per hectare) did not damage corn production (table II).

h) the superiority noted in the production of all the treatments with the exception of $2 \mathrm{~A}$, which damaged the plants, we atribute to the lack of competion between corn and weeds; all chek-plots suffered this competition, because they were not miltivatad 
Probably, there was, also, hormonial effect of 2,4-D on the corn plant.

Not withstanding the fact that the present experiment has been successful, we think that new researches are necessary, especially with the purpose of studying factors as climate and soil which in other countries, interferred with the success of the pre-emergence weed control.

\section{AGRADECIMENTOS}

Somos gratos a Blemco S. A. representante da Dow Chemical Company, pelos produtos utilizados nesta pesquisa. Estendemos os nossos agradecimentos ao Dr. Frederico Pimentel Gomes que mui gentilmente fez a análise estatística dos resultados.

\section{BIBLIOGRAFIA}

1 - ALBAN, E. K. and V. E. Keirns. 1948 - Pre-emergence and post-emergence weed control in vegetable crops with 2,4-D, and oil. 51:526-532.

2-ANDERSON, J. C. and D. E. Wolf. 1947 - Pré-emergence of weeds in corn with 2,4-D. Journal American Society of Agronomy, 39: 341-342.

3-ARAKERI, H. R. and R. S. Dunham. 1950 - Eviromental factors relating to the pre-emergence treatment of corn with 2,4-D and Soybeans with TCA. Technical Bulletin 190. University of Minnesota.

4-DEARBORN, C. H. e Sweet, R. D. and Havis, J. R. $1948-$ Weeding sweet cornwith 2,4-D : effects of timing, rates and varieties. Proceedings of the American Society for Horticultural Science. 5 1: 536-540.

5 - ELLIS, N. K. and Bullard, E. T. 1948 - Varietal response of sweet corn to 2,4-D. spray and the effect of different for mulations of 2,4-D on yield. Proceedings of the American Society for Horticultural Science. 51: 505-508.

6-HAMNER, C. L.; Tukey, H. B.; Carbon, R. J. 1948 - 2,4-D no milho. A Fazenda. 43 (6) : 44.

7 - HELM, C. A. 1951 - The use of pre-emergence sprays in corn production. Down to Eath 6 (4) : 12.

8-LEE, Oliver C. 1948 - Suggestions for weed control in corn with 2,4-D. Down to Earth 4 (1): 6-7.

9 - WARREN, G. F. and T. P. Hernandez. 1948 - Weed control in certain vegetable crops with soil applications of 2,4-D. Proceedings of the American Society for Horticultural Science 51: 515-525. 


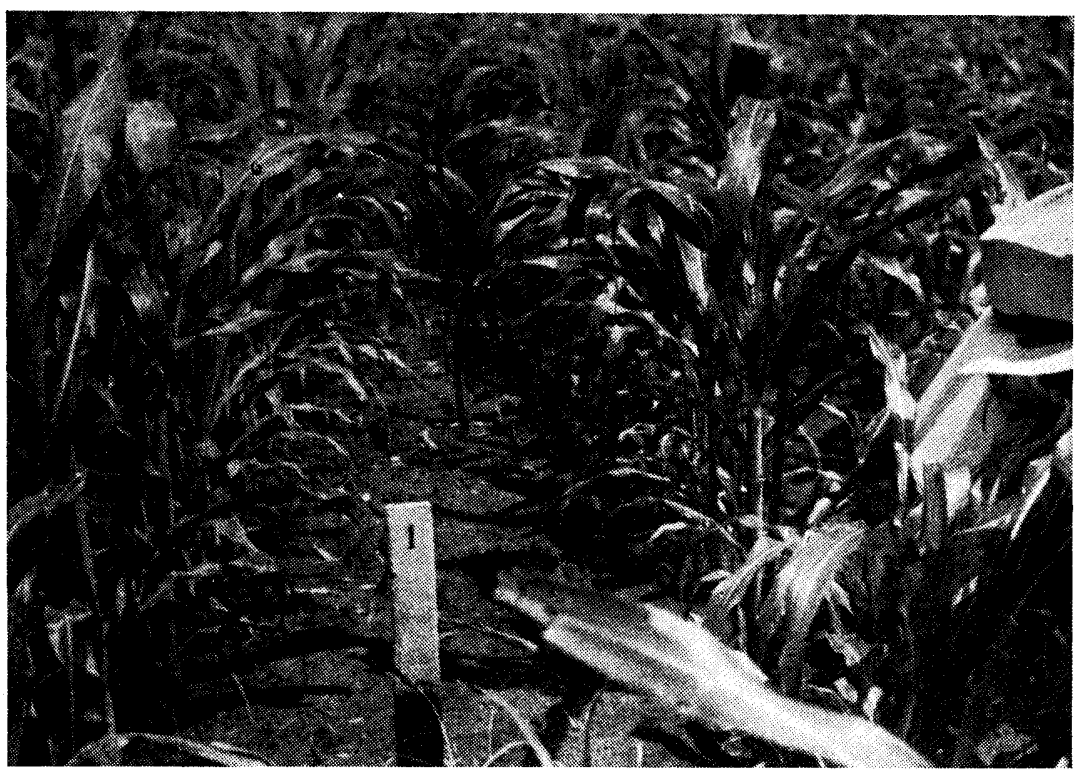

Foto I - Tratamento 1A

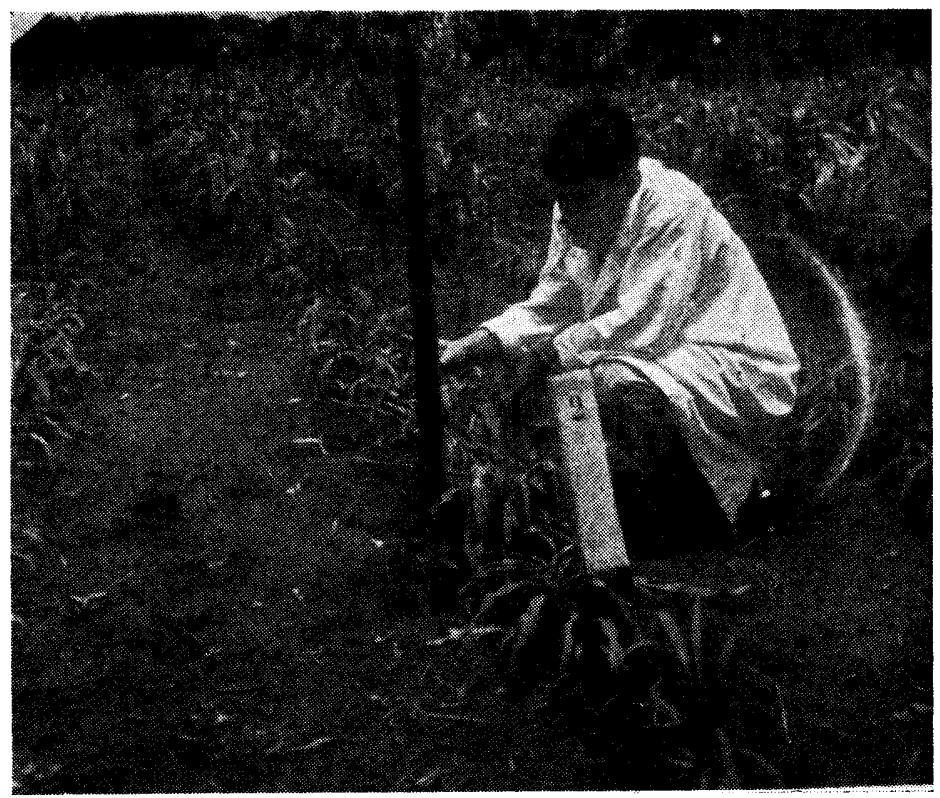

Foto II - Tratamento $2 \mathrm{~A}$ 


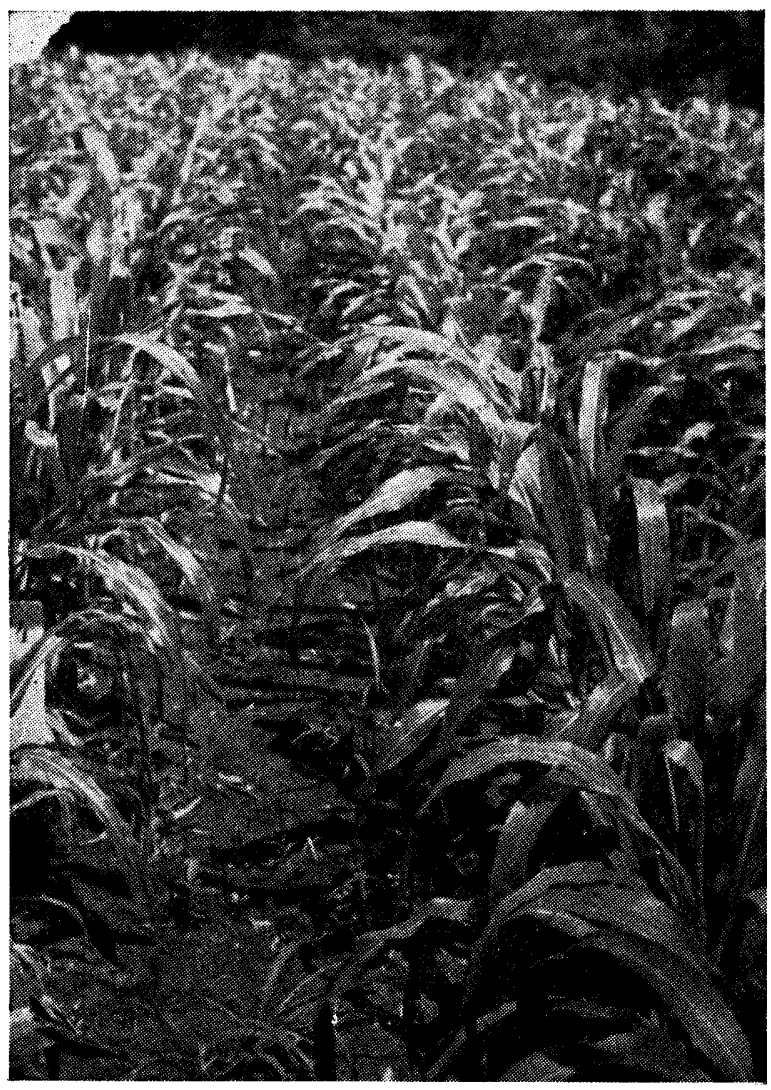

Foto III - Tratamento $4 \mathrm{~A}$ 


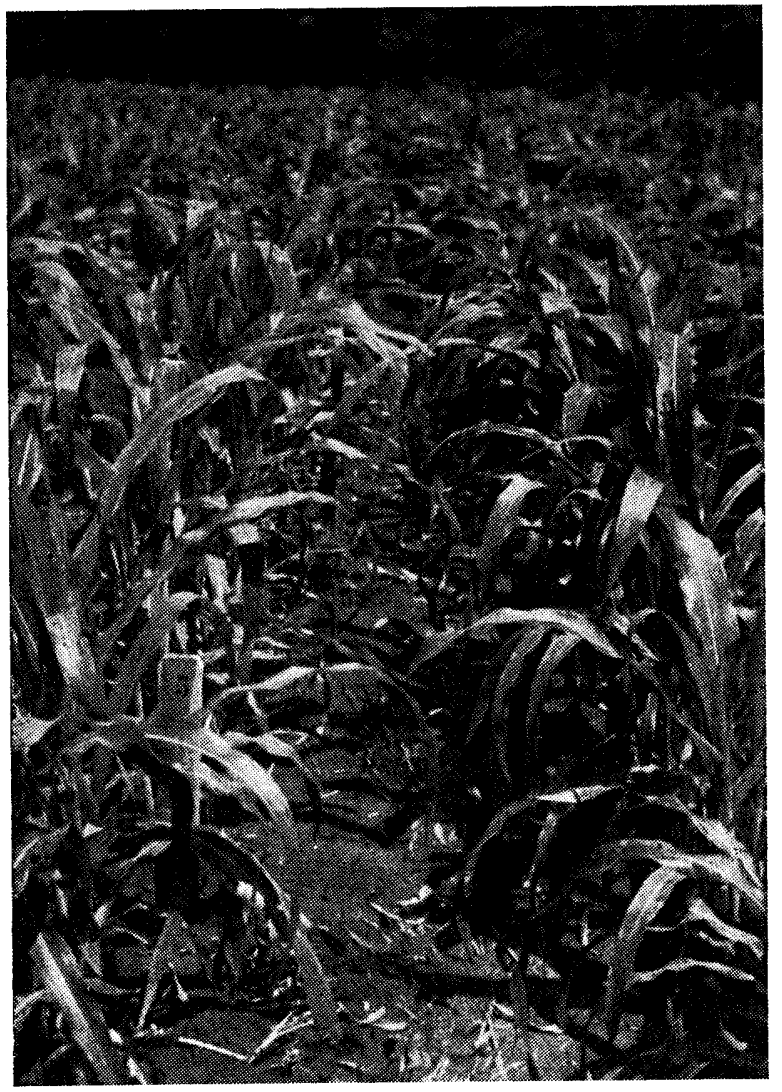

Foto IV - Tratamento 5A 


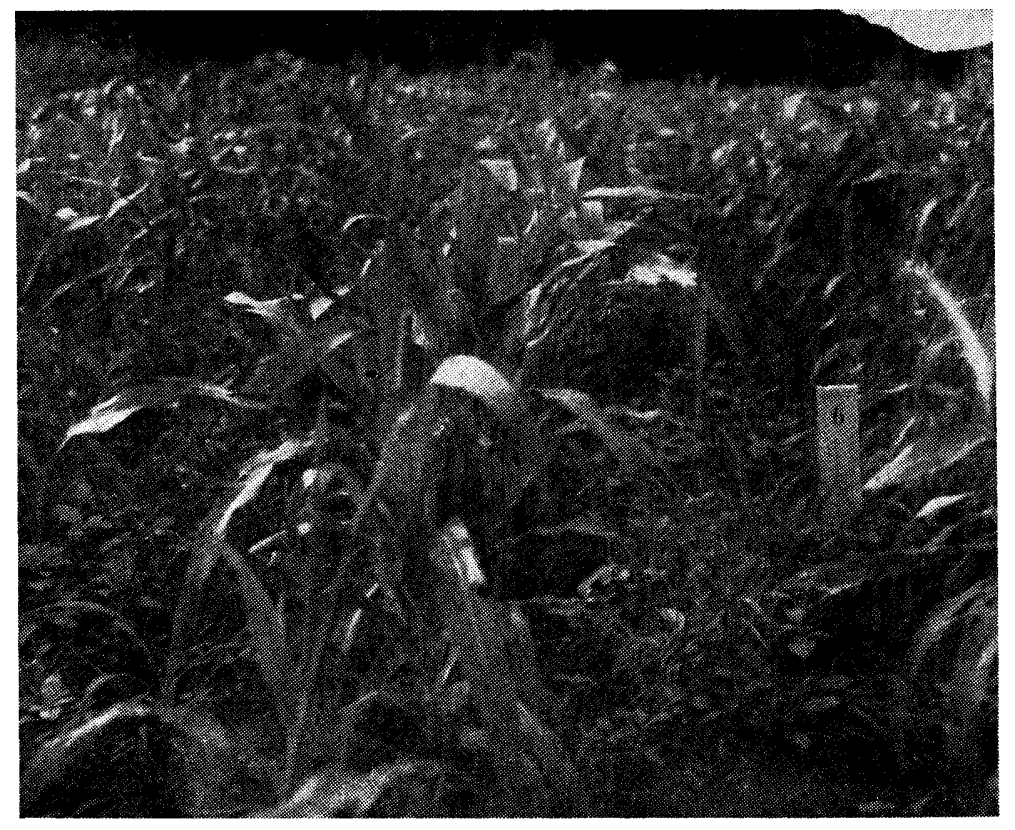

Foto V - Testemunha 


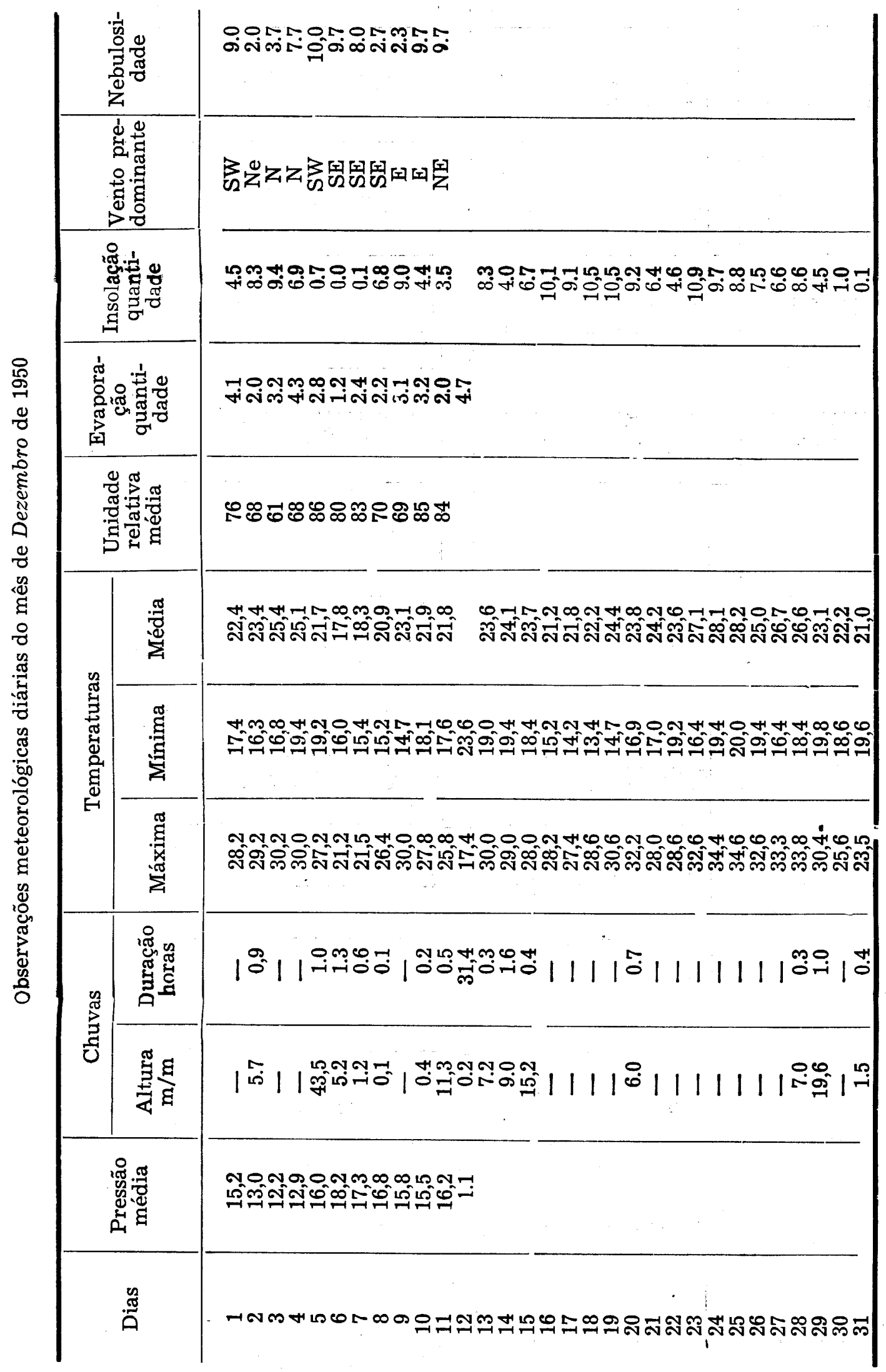


